\title{
Teko Haw Brasil
}

\section{Regina de Paula ${ }^{1}$}

Resumo: Este texto dá voz aos indígenas da aldeia Maracanã no Rio de Janeiro, abordando questões relacionadas à universidade indígena, à tensão entre 0 asfalto e a terra, ao pertencimento, à problemática do indígena urbano, à oralidade e ao projeto Teko Haw Brasil, desenvolvido pela autora.

Palavras-chaves: Aldeia Maracanã. Questão indígena. Oralidade. Arte contemporânea.

\section{Teko Haw Brazil}

Abstract: The author assembles indigenous voices from the Maracanã Village in Rio de Janeiro in order to examine issues related to the creation of an indigenous university, to the tensions between asphalt and land, to the sense of belonging, to urban indigeneity, to orality, and to the artistic Project Teko Haw Brasil.

Keywords: Maracanã Village. Indigenous Peoples. Orality. Contemporary Art.

1 Regina de Paula é artista e professora adjunta do Instituto de Artes e do PPGartes da Uerj. Foi artista residente do Centre d'Art Passerelle, em Brest, França (2005). Realizou Diante dos olhos, os gestos (2016), exposiçãa individual que ocupou todo um andar no Paço Imperial do Rio de Janeiro, com curadoria de Ivair Reinaldim, e, em coautoria com Marcelo Campos, lançou o livro Sobre a areia (2016). Participou da exposição coletiva O Rio dos navegantes, no Museu de Arte do Rio (2019), e Esqueleto70, no Paço Imperial do Rio de Janeiro (2019). Atualmente seu trabalho é voltado, sobretudo, para a questões fundadoras da nossa cultura, a partir de sua vivência na aldeia Maracanã. E-mail: reginadepaula1@gmail.com; ORCID: https://orcid.org/0000-0002-0796-9151; Instituição filial: Universidade do Estado do Rio de Janeiro; País: Brasil. 
Nunca tive cultura nem lia nada, a cultura que tive foi a minha convivência com o Mário Pedrosa e o Mário Schenberg, eles me engravidaram os ouvidos com tudo que era interessante e bom. ${ }^{2}$

A maioria dos que circulam pela Radial Oeste e cercanias, na altura do estádio do Maracanã, no Rio de Janeiro, não imagina que aquele casarão que um dia foi o Museu do Índio e sua área de entorno constituem uma das resistências político-culturais mais importantes do Rio de Janeiro na atualidade. Trata-se da aldeia Maracanã, um espaço de manejo comunitário, gerido por indígenas de diversas etnias, residentes ou em passagem pela cidade do Rio de Janeiro, onde vem sendo implantada a Universidade Indígena Pluriétnica Aldeia Maracanã. Mas o que seria uma universidade indígena?

Depende do que nós entendemos por universidade indígena e, nesse sentido, a universidade indígena é qualquer aldeia; ela não precisa ter um curso, ter uma atividade, uma vivência (...) porque ela é a própria vivência cotidiana. A aldeia nas suas tarefas de viver, simplesmente viver, já tem uma universidade, porque antigamente nas aldeias tradicionalmente não existia isso, de gente que fala sobre o ensino especial indígena, sobre a educação especial. Isso é só uma questão de uma necessidade, uma demanda que os povos originários têm para interagir, já que fomos forçados a interagir com essa sociedade. A gente não pediu pra vir, essa coisa toda. Enfim, já que teve todo esse impacto, esse contato traumático, a gente quer interagir de uma maneira plena. A gente quer ter os mesmos diretos que as pessoas têm, já que a gente é brasileiro, e o próprio presidente diz que a gente é; nada de vários povos aí, é só brasileiro; a gente também está nesse território aqui, a gente faz parte também, a gente tem a nossa identidade enquanto povos originários, mas também somos parte disso aqui querendo ou não. A gente já que foi forçado em termos de história, dessa violência que eles cometeram, temos toda essa relação inevitável. A gente tem que se relacionar (...). Não tem que ter "ah já que você é indígena você vai pro mato então". Não!

(...) a gente inclusive usa o termo "universidade" que é forma de dialogar (...) para as pessoas verem que aqui há um ensino, há uma pedagogia, há

\footnotetext{
${ }^{2}$ CLARK apud ROLNIK, Suely. Molda-se uma alma contemporânea: o vazio-pleno de Lygia Clark. Disponível em: http://www4.pucsp.br/nucleodesubjetividade/Textos/SUELY/Molda.pdf, p.33. Acesso em 25 dez. 2019.
} 
uma educação acontecendo, um processo educativo; e você pode vir para interagir com a gente, é só isso. O nome é irrelevante, o que vale são as atividades. (...) Tem vivências de agroecologia, de plantio, de construção com pau a pique, vai ter inclusive agora uma vivência de construção com tijolos de adobe, mutirão pra limpeza, pra plantio, enfim são vários tipos de artesanato, os parentes ali ensinando como fazer os diversos tipos de artefatos; então isso é universidade. Ou então é só você ir lá e estar com a gente conversando lá, e a gente vai aprendendo um com o outro, e isso já é universidade também, isso é o sentido mais profundo do que a gente entende como universidade (Dário Jurema).

Figuras 1 e 2

Teko Haw Brasil.

Aldeia Maracanã, 19

de maio de 2018.

Fotografias: Wilton

Montenegro

(esquerda) e Fabiano

Araruna (direita)
Em 22 de março de 2013 a aldeia Maracanã sofreu um ataque com armas químicas e sônicas, ${ }^{3}$ estas últimas utilizadas pela primeira vez no Brasil, numa operação promovida pelo governo do estado do Rio de Janeiro, que concedeu a área para a construção de um estacionamento e instalações comerciais vinculadas à Copa do Mundo de 2014. O terreno foi asfaltado, desrespeitando os modos de vida dessa comunidade. Em 2016 os indígenas voltaram a ocupar o local. A posse da área continua em disputa judicial. 4
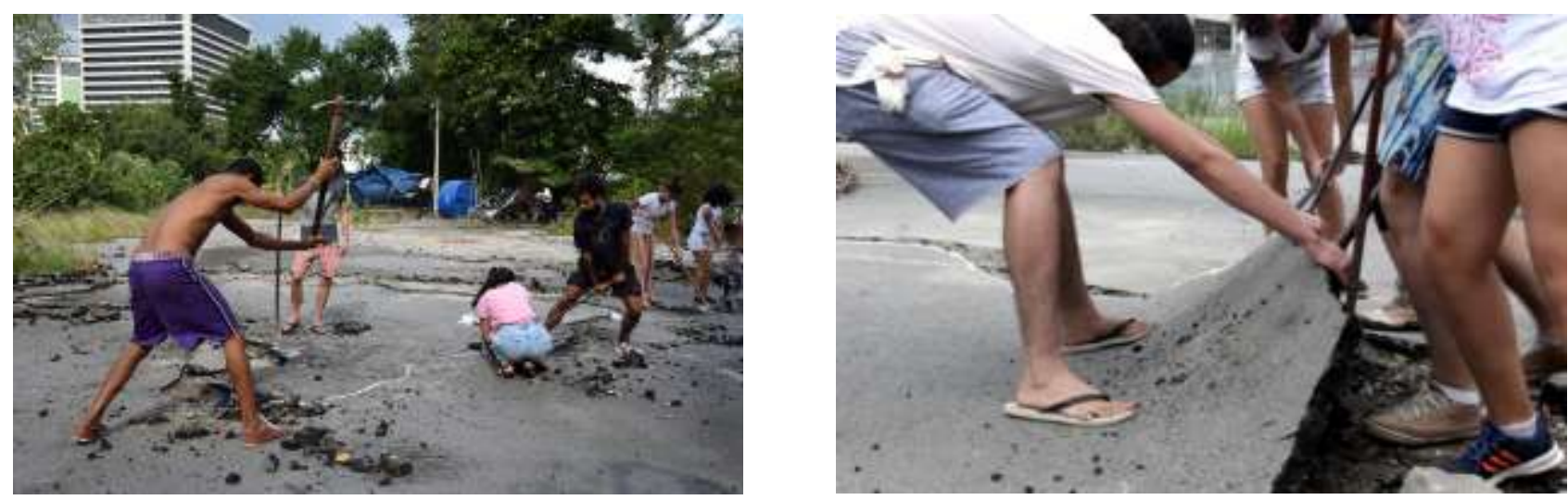

${ }^{3}$ COLETIVO CAUIM. CAUIM: Aldeia Maracanã ou com quantos extermínios se (des)faz um país. VIOMUNDO, 14 mar. 2013. Disponível em: <https://www.viomundo.com.br/politica/coletivocauim-aldeia-maracana-ou-com-quantos-exterminios-se-desfaz-um-pais.html>. Acesso em: 12 nov. 2019.

${ }^{3}$ DEUS, Joanice de. Asfalto deve passar em terras indígenas. Diário de Cuiabá, oo 15.285, 16 ago. 2019. Disponível em: <http://www.diariodecuiaba.com.br/detalhe.php?cod=526894>. Acesso em: 12 nov. 2019.

${ }^{4}$ Mais informações na petição online a favor da aldeia, elaborada por um grupo do qual fiz parte, disponível em <www.change.org/aldeiamarakana>. 
A tensão entre o asfalto e a terra não é exclusiva da aldeia Maracanã; tem sido uma constante na questão indígena. $\hat{E}$ o sal na terra, salgar pra ninguém mais ter que voltar ali (Dário Jurema).

De acordo com o [atual] governador Mauro Mendes, em audiência realizada no município de Água Boa (720 quilômetros de Cuiabá), o ministro da Infraestrutura, Tarcísio Gomes, já teria informado que o denominado Contorno Leste, que desviaria o trajeto das terras indígenas dos índios Xavantes, será descartado pelo atual governo de Jair Bolsonaro. ${ }^{5}$

Além da ocupação ilegal dos seus territórios, os indígenas vêm sofrendo com o confinamento em terras indígenas. (...) Em regiões superpovoadas, imprensados entre as cercas das fazendas e o asfalto das rodovias, a incidência do suicídio é ainda maior, principalmente entre os jovens. Também são vítimas de atropelamento, e até mesmo a violência entre eles é maior, por conta da disputa por áreas de plantio. ${ }^{6}$

O Instituto de Pesquisa Ambiental da Amazônia (IPAM) elaborou dois mapas da região, que mostram as áreas desmatadas ao redor da BR-317 até 2008 e a simulação da sua progressão em 2030. O diagnóstico aponta que a "madeira, a pecuária e a agricultura são os principais vetores do desmatamento, mas esta dinâmica é intensificada com a chegada do asfalto", conclui Sonaira Souza, pesquisadora do IPAM. $^{7}$

E o asfalto é um aspecto assim muito simbólico disso tudo. A gente quando entrou lá [na aldeia Maracanã] arrancou o primeiro bloco de asfalto (...)é energia da nossa mãe terra que tá ali embaixo, onde a gente planta (...). Tudo isso é a vida voltando, ao que era o árido, aquela coisa morta que eles tentaram fazer, mas não tá morta, só tá adormecida, escondida, sufocada ali embaixo (...) Hoje já tem a floresta, a florestinha em várias áreas que foi voltando aos pouquinhos, a gente plantando, arrancando asfalto $e$ plantando, arrancando asfalto e plantando (...) Essa é a nossa verdade, $e$ tudo isso é a vida voltando aos pouquinhos (Dário Jurema).

\footnotetext{
${ }^{5}$ DEUS, Joanice de. Asfalto deve passar em terras indígenas. Diário de Cuiabá, no 15.285, 16 ago. 2019. Disponível em: <http://www.diariodecuiaba.com.br/detalhe.php?cod=526894>. Acesso em: 12 nov. 2019.

${ }^{6}$ Redação RBA. Relatório mostra aumento da violência contra povos indígenas no Brasil. Rede Brasil Atual, 26/09/2019. Disponível em: <https://www.redebrasilatual.com.br/cidadania/2019/09/relatorio-mostra-aumento-daviolencia-contra-povos-indigenas-no-brasil/>. Acesso em: 12 nov. 2019.

${ }^{7}$ COELHO, Maria Emília. Asfalto novo rasga floresta. ((o))eco, 26 out. 2010. Disponível em: <https://www.oeco.org.br/oecoamazonia/asfalto-novo-rasga-floresta/>. Acesso em: 12 nov. 2019.
} 

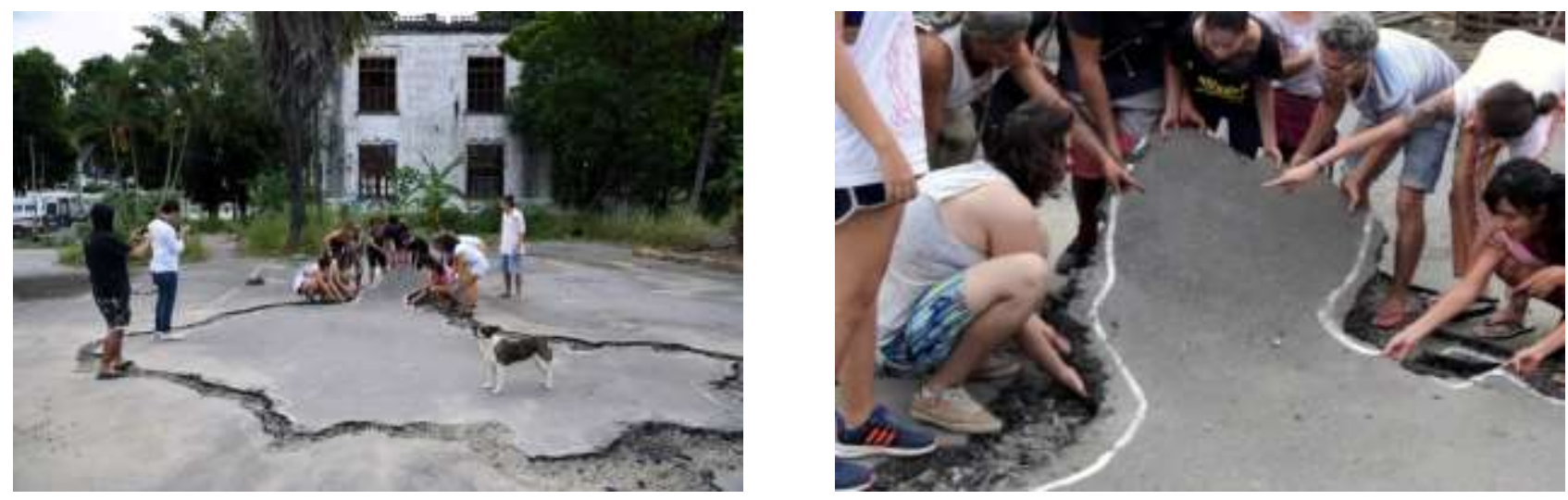

Figuras 3 e 4 Regina de Paula, Teko Haw Brasil. Aldeia Maracanã, 19 de maio de 2018. Fotografias: Wilton Montenegro (esquerda) e Fabiano Araruna (direita). Participação dos alunos do Instituto de Artes, Uerj
Cheguei à aldeia Maracanã com ralo conhecimento da causa; a primeira vez foi em um evento em torno da projeção do filme Martírio, do cineasta Vincent Carelli, seguido de depoimentos contundentes de indígenas de diversas etnias. Passei a ouvir, de todos os lados. Alguns dizem que a situação da aldeia é complicada, ambígua, porque reivindicam um lugar na cidade, considerando que o lugar dos indígenas é na floresta e que esses, por viver na cidade, já estariam aculturados. A maioria nunca esteve na aldeia.

É interessante até ler Os índios e a civilização, de Darcy Ribeiro, e num trecho lá, ele fala, quando menciona os povos do nordeste, ele cita os xukurus, ele próprio o Darcy Ribeiro que é um camarada que tem uma postura assim realmente bem simpática aos indígenas, defensor, ele fala "ah, eles não são mais indígenas" (...) eles não têm mais a língua, falam o português, já estão miscigenados, não têm traços indígenas praticamente, parecem com qualquer caboclo da região. Ele diz que essa identidade indígena ali é uma coisa imponderável. Esse imponderável está além do que possa imaginar. É uma linhazinha que segura toda uma tradição, toda uma ancestralidade que se mantém ali. Eu sou xucuru (Dário Jurema).

(...) hoje mais da metade da população indígena brasileira vive nas cidades, então ela está sujeita a essas questões que a gente está levantando aqui e nas quais a aldeia Maracanã tem uma importância ímpar. Se a gente não trabalhar essa necessidade, de esses indígenas terem espaços nos meios urbanos para afirmar sua identidade, para praticar sua cultura, defender seus direitos, para conviver com seus parentes, a gente vai estar mais perto desse processo de aculturação. Que, teoricamente, é uma farsa, pois não define alguém. A definição da identidade aí é realizada por um terceiro, uma autoridade, por negação. 
No Censo, da década de 1990 para os anos 2000, houve uma multiplicação da população indígena, principalmente no meio urbano, que o IBGE não conseguia explicar do ponto de vista matemático (convencional). (...) $A$ equação do crescimento vegetativo, quantos filhos nasceram e tal, não dava conta de explicar tal crescimento. Então, o que aconteceu? Eles tinham que mudar, talvez a equação matemática não se adequasse ao paradigma da autoafirmação? Teriam então que adotar uma equação quântica, mas, entender não é preciso, controlar é preciso: reduzir a autoidentificação aos falantes da língua indigena. (...) Imagina se todo mundo começasse a pensar que tem ancestralidade indígena e que de certa forma a cultura indígena pauta a sua forma de ser e pensar, o seu desejo por um mundo melhor e começa a se afirmar indígena. Isso vai trazer um problemaço para os demógrafos. Então, de certa forma, eles estão tentando controlar esse fenômeno (Fernando Tupinambá).

Mas por acaso cobram que o descendente de italiano tem que falar italiano? Que o negro tem que falar a língua da etnia da qual ele veio na África que ele nem sabe qual? Só o indígena tem que saber tudo, tem que saber falar a língua, tem que se vestir que nem, é uma coisa assim de louco, todo o resto pode ser, menos o indígena, por mais que cada povo tenha a sua própria autonomia de determinar quais são os seus critérios de pertencimento (Dário Jurema).

Se alguns questionam a legitimidade da aldeia, outros apoiam a parcela de indígenas que estava na aldeia Maracanã antes do confronto de 2013 e que fez acordo com o Estado. Apesar de não mais frequentarem o local, curiosamente, ainda se autointitulam aldeia Maracanã.

Vinte e duas famílias de índios que antes ocupavam o antigo Museu do Índio, no Maracanã, ganharam apartamentos entre as 998 unidades do empreendimento do projeto Minha Casa, Minha Vida, que a presidente Dilma Rousseff inaugurou no fim da tarde desta segunda-feira, na área do demolido presídio Frei Caneca. Ela chegou ao local por volta das $18 \mathrm{~h}$, acompanhada do governador Luiz Fernando Pezão. Das 22 famílias, 20 irão ocupar um bloco inteiro. Já há, inclusive, uma brincadeira entre eles, que elegerão um síndico ou um cacique para cuidar do local. ${ }^{8}$

\footnotetext{
${ }^{8}$ MAGALHÃES, Luiz Ernesto. Índios do Maracanã são reassentados na área do antigo presídio Frei Caneca. O Globo, 30 jun. 2014. Disponível em: <https://oglobo.globo.com/rio/indios-domaracana-sao-reassentados-na-area-do-antigo-presidio-frei-caneca-13082451>. Acesso em: 15 nov. 2019.
} 
Mais uma vez mirei o solo e pensei nas camadas da aldeia Maracanã soterradas pelo asfalto. Numa terça-feira, 8 de maio de 2018, ansiosa, fui encontrar José Urutau Guajajara, uma das atuais lideranças da aldeia, para compartilhar a ideia de desenhar o contorno de um grande mapa do Brasil naquele terreno asfaltado e retirar de seu interior a camada de asfalto, dando assim origem a uma planta baixa do Brasil em terra. Devolver à aldeia parte de seu solo sagrado, do solo Brasil. A ação viria a se chamar Teko Haw Brasil.

Então a professora Regina chega à aldeia Maracanã: "Urutau eu tenho um projeto. Eu não dormi direito pensando nesse projeto", e aí eu tinha certeza que já ia ser aprovado antes de ela dizer o que era. (...) Qual o projeto? Eu nem sabia e já estava aprovado. O projeto é esse. Precisamos fazer, ainda não nem tem nome, o mapa do Brasil e tirar daqui o asfalto (José Urutau Guajajara).

Guardo uma imagem desse dia, registrada pelo meu celular, José desenhou com pequenas pedrinhas um mapa do Brasil no asfalto. "A hospitalidade consiste em interrogar quem chega? (...) Ou será que a hospitalidade começa pela acolhida inquestionável, num duplo apagamento, o apagamento da questão e do nome? nos interroga o filósofo Jaques Derrida. ${ }^{9}$ Eis aqui um exemplo singelo de uma das grandes lições que a aldeia proporciona aos que ali se dispõem a conviver. Acolhimento e hospitalidade para nós, que ali poderíamos ser o outro, o bárbaro, o estrangeiro.

9 DERRIDA, Jacques. Anne Dufourmantelle convida Jacques Derrida a falar Da Hospitalidade. Tradução de Antonio Romane. São Paulo: Escuta: 2003, p.25, 27. 
Figura 5

Regina de Paula. Aldeia Maracană, 8 de maio de 2018. Fotografia: Regina de Paula

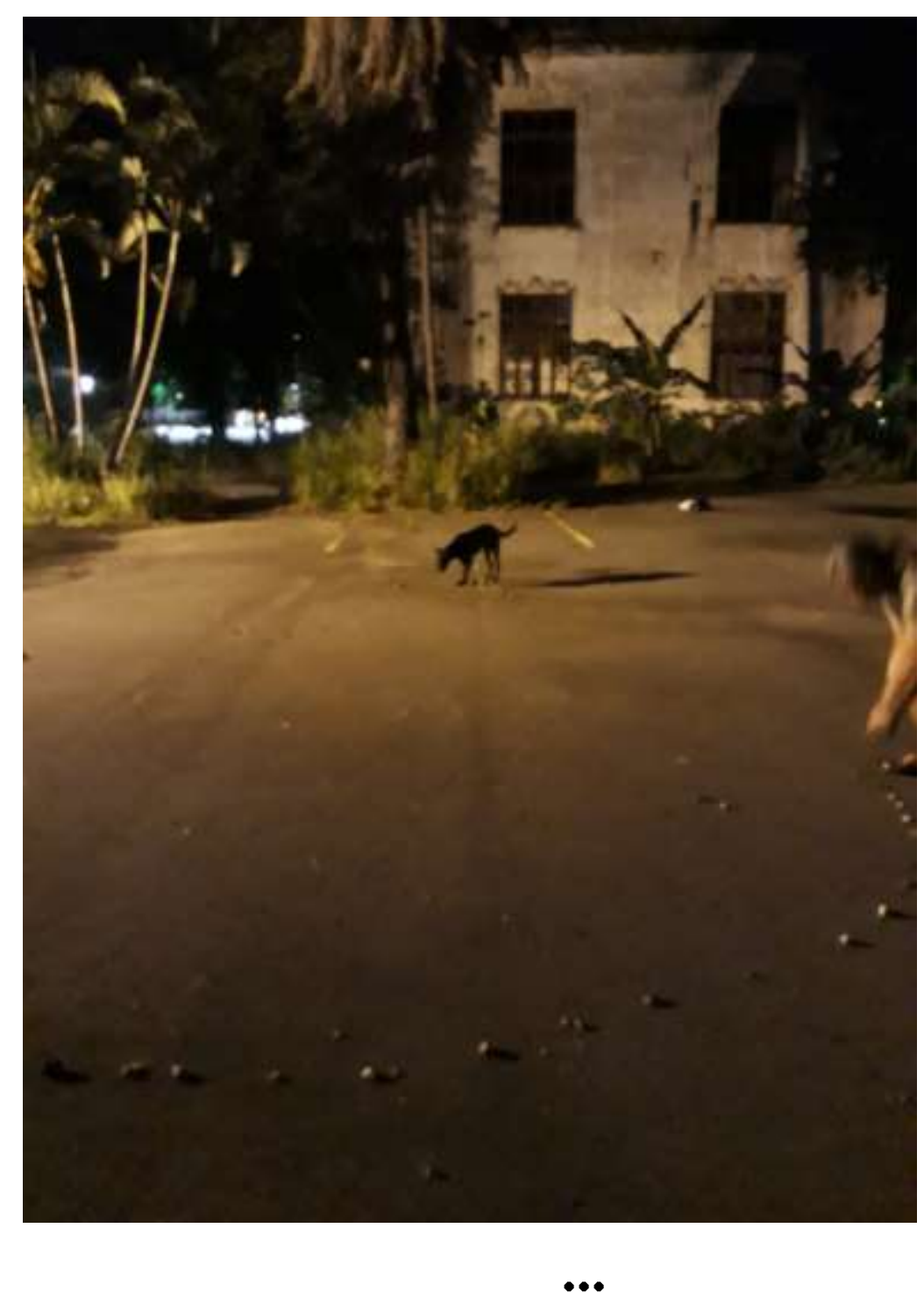

O filósofo Walter Benjamim em "Experiência e pobreza" (1933) e "O narrador" (1936) trata de um conceito que hoje nos é caro: o empobrecimento ou mesmo a perda da experiência. O contexto histórico é o período entreguerras, a iminência do nazismo. "Quem ainda encontra pessoas que saibam contar histórias como devem ser contadas?"10 é a pergunta que se faz o filósofo. Hoje, numa época de disseminação de
${ }^{10}$ BENJAMIN, Walter. Experiência e Pobreza. In: Magia e técnica, arte e política: ensaios sobre literatura e história da cultura. Tradução de Sérgio Paulo Rouanet. São Paulo: Brasiliense, 1996, p.114. 
notícias falsas, que se propagam no impalpável espaço virtual como um vírus, pensamos novamente no que está rompido.

O jornal britânico The Guardian publicou hoje um artigo descrevendo os três perfis de brasileiros que usam o WhatsApp e ajudam a eleger Jair Bolsonaro (PSL) como presidente. (...)

As fake news, notícias falsas, são usadas nas campanhas políticas deste ano, e o app de mensagens é uma das principais fontes de notícias dos brasileiros, de acordo com um estudo conduzido pelo Instituto Reuters de Jornalismo em parceria com a Universidade de Oxford e com a BBC, divulgado no ano passado.

Os três perfis são chamados pelo The Guardian de brasileiros médios, Bolsominions e influenciadores. $O$ artigo é assinado por David Nemer, professor-assistente da Escola da Ciência da Informação, na Universidade de Kentucky, nos Estados Unidos. ${ }^{11}$

Batendo continência e pisando firme no chão, como se estivessem num quartel do recruta zero, dezenas de aloprados de todas as idades deram um espetáculo grotesco de falta de noção durante um protesto contra o STF em que pediam a cabeça do ministro Gilmar Mendes.

De que toca saiu essa gente estranha, um gado humano perdido no tempo e no espaço? ${ }^{12}$

Vivemos um contínuo apagamento da memória que remonta a nossa origem. "Desde 1500 tem mais invasão do que descobrimento" cantou na avenida a Mangueira, escola de samba vitoriosa do carnaval carioca de 2019 , nos lembrando daqueles que não estão mais presentes e que não devem ser esquecidos.

Brasil, meu nego

Deixa eu te contar

A história que a história não conta

$O$ avesso do mesmo lugar

Na luta é que a gente se encontra ${ }^{13}$

${ }^{11}$ AGRELA, Lucas. Os 3 perfis de usuários do WhatsApp que ajudam a eleger Bolsonaro. Exame, 25 out. 2018. Disponível em: <https://exame.abril.com.br/tecnologia/os-3-perfis-de-usuarios-dowhatsapp-que-ajudam-a-eleger-bolsonaro/>. Acesso em 27 dez. 2019.

12 KOTSCHO, Ricardo. Hospício Brasil: a 'marcha das loucas' diante da estátua da Havan. Diário do Centro do Mundo, 18 nov. 2019. Disponível em: <https://www.diariodocentrodomundo.com.br/hospicio-brasil-a-marcha-das-loucas-diante-daestatua-da-havan-por-ricardo-kotscho/>. Acesso em: 10 nov. 2019.

13 "Histórias para ninar gente grande”. G.R.E.S. Estação Primeira de Mangueira. De Deivid Domênico, Tomaz Miranda, Mama, Marcio Bola, Ronie Oliveira e Danilo Firmino. 
De outro modo, como aponta a psicanalista Claudia de Moraes Rego, a partir de Derrida, "trata-se de aprender a viver com os fantasmas. Estar entre os fantasmas é uma política da memória, da herança e das gerações". 14 Retomando Walter Benjamin, diz a psicanalista, "em oposição à história contada pelos vencedores, sempre comemorativa dos grandes feitos, Benjamin propõe a rememoração que é uma ascese da atividade historiadora porque se abre ao buraco, ao esquecido, ao recalcado". ${ }^{15}$

A oralidade e os saberes ancestrais permeiam as culturas indígenas. No dia 1 o de agosto de 2019, no auditório do Museu de Arte do Rio (MAR), numa programação paralela à exposição O Rio dos navegantes, foram exibidos o filme Teko Haw Brasil, resultado desse projeto que concebi na aldeia Maracanã, e José//Urutau//Guajajara: a ave fantasma, um curta sobre essa liderança da aldeia, que realizei em parceria com Wilton Montenegro. O evento contou com a presença de alguns indígenas da aldeia, e as falas que reproduzo neste ensaio foram registradas nesse dia.

E assim nasceu o que não tinha nem nome ainda. Olha vamos colocar uma palavra em tupi, os M'bya Guarani iam chamar Teko'a Brasil. Os Kaiowa iam chamar Teko Ha Brasil e os Tantehar-Guajajara, Teko Haw Brasil que é uma diferença dialetal em três povos falantes do mesmo tronco linguístico. (...) Então professora, foi aprovado na hora também mais um nome bacana, ficou em tupi mais um Brasil. Mas faltava mais alguma coisa (José Urutau Guajajara).

Realizada a retirada do asfalto José ponderou que aquele mapa do Brasil ia ficar pelado depois de tirado o asfalto todo (...). Eu não sei muito bem, só sei que tive a ideia (...), já que Rondon fez isso na década de 1920, 1930, vamos fincar uma pedra (...), mas uma pedra mesmo, o marco temporal.

A ideia de "marco temporal" surgiu no julgamento pelo Supremo Tribunal Federal (STF) em relação à reserva Raposa do Sol, preconizando que indígenas só teriam direito a terras que ocupavam em 1988, momento da promulgação da Constituição. $\mathrm{Na}$ decisão, a maioria dos ministros apontou que a tese não deveria ser aplicada automaticamente em outros casos. Apesar disso, a Advocacia-Geral da União

\footnotetext{
${ }^{14}$ REGO, Claudia de Moraes. Rexistência do que ex-iste. Rio de Janeiro, trabalho não publicado, p.2, 2019.

15 REGO, op. cit., p.4.
} 
Figuras 6 e 7 Regina de Paula, Teko Haw Brasil. Colocação do marco temporal por José Urutau

Guajajara e Zawaruhu

Marcelo Tembe. Aldeia Maracanã, 31 de maio de 2018. Fotografia: Wilton Montenegro elaborou um parecer, vinculando toda administração pública, baseado nesta concepção. ${ }^{16}$

A palavra marco geralmente é utilizada para designar um sinal de demarcação; aquilo que marca uma época ou uma data; ponto de referência ou fronteira. ${ }^{17}$

Verificamos, portanto, que os marcos possuem para além de sua finalidade geográfica e demarcatória (prática) uma expressão simbólica, de centralidade de origem, de elevação ou mesmo de status pretendido. ${ }^{18}$

O Korubo é uma peça fundamental na discussão do marco temporal, porque logo depois que nós fincamos a pedra ali, que é aquela pedra que vocês viram, o Korubo tem a ideia (...) depois de deflagrar o governo Bolsonaro, de queimar o boneco do Bolsonaro, exatamente no marco temporal. Então diversas vezes ele fez o boneco dizendo que esse governo está ardendo em Brasília, está queimando em Brasília, e nada mais simbólico que queimar o Bolsonaro no marco temporal, ali na aldeia Maracanã (José Urutau Guajajara).
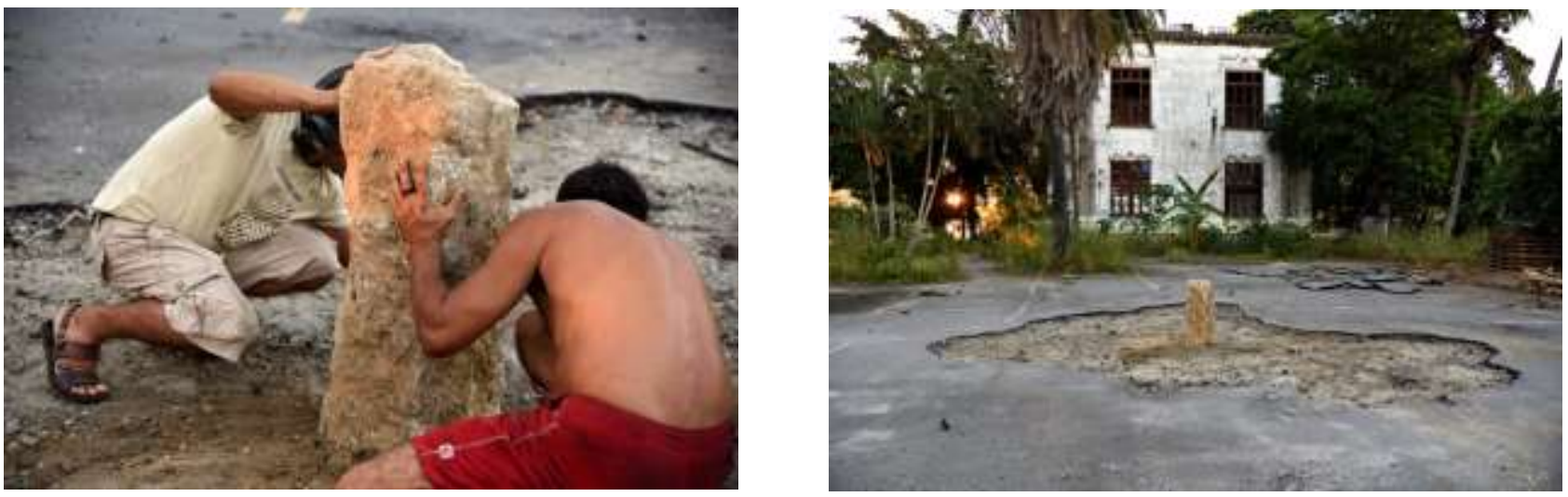

16 TATEMOTO, Rafael. Marco temporal que limita a demarcaçăo de terras indígenas avança na Câmara. Brasil de Fato, Brasília, 31 maio 2018. Disponível em: <https://www.brasildefato.com.br/2018/05/31/marco-temporal-que-limita-a-demarcacaode-terras-indigenas-avanca-na-camara/>. Acesso em: 20 nov. 2019.

17 SAMPAIO, Renata Domingos. Para além da excepcionalidade: a patrimonialização do monumento indígena Marco Zero Kadiwéu. 2018. Dissertação (Mestrado em Preservação do Patrimônio Cultural). Instituto do Patrimônio Histórico e Artístico Nacional, Rio de Janeiro, 2018, p.126. Disponível em: <http://portal.iphan.gov.br/uploads/ckfinder/arquivos/Disserta\%C3\%A7\%C3\%A30\%20para\% 20dep\%C3\%B3sito_27_11_18-merged.pdf>. Acesso em: 12 nov. 2019.

18 SAMPAIO, op. cit., p.130-131. 
Surge um problema agora porque onde foi tirado o asfalto o capim cresce, e para os corredores dali, para quem mora no entorno dali [os moradores da vizinhança que transitam na pista esportiva em volta do estádio Maracanã], capim, mato, verde, compostagens para eles é lixo (José Urutau Guajajara).

Aquele lixo urbano chamado Aldeia Maracanã é um absurdo. E é logo em um dos trechos mais importantes sob o ponto de vista logístico, numa área que liga a Zona Norte à Zona Sul, bem do lado do Maracanã. O espaço poderia servir como estacionamento, shopping, área de lazer ou equipamento acessório do próprio estádio do Maracanã. Como carioca, me causa indignação ver aquilo do jeito que está hoje. Quem gosta de índio, que vá para a Bolívia, que, além de ser comunista, ainda é presidida por um índio. ${ }^{19}$

De quem é a aldeia Maracanã? É das famílias que ocupam aqueles lugares lá? Não! É de milhares de famílias que a gente sequer reconhece. Que deveriam ter acesso a este espaço para afirmar sua cultura (...) Essas pessoas foram renegadas há tanto tempo que não percebem que aquele espaço é seu. Reproduzir ali um centro cultural, mostrar a cultura indígena pra gringo ver, para isso tem o Museu do indio lá em Botafogo. A principal função da aldeia Maracanã é a autoafirmação indígena (Fernando Tupinambá)

Qual é a diferença da terra indígena, da posse indígena, para a posse civil ou particular? A destinação, se destina terra indígena para os usos, os costumes $e$ as tradições. (...) Dar destinação à vida (...) Nós costumamos falar que somos os caseiros, nós não somos proprietários e nem queremos romper esse princípio constitucional, esses valores nenhum indígena é contra (...). Nós não estamos lutando por propriedade (Arão Providencia Guajajara).

E eu estou aqui desde 2006 participando para dar resistência à aldeia Maracanã e não vou desistir. Eles podem retirar, retirar, retirar, cinco vezes e vou voltar de novo, para os meus netos, meus filhos e para todos que querem ver um pouco da nossa cultura (Potira Krikati Guajajara).

\footnotetext{
19 Deputado Rodrigo Amorim, apud CAPPELLI, Paulo. “Aldeia Maracanã é lixo urbano. Quem gosta de índio, vá para a Bolívia”, diz Rodrigo Amorim. O Globo, 4 jan. 2019. Disponível em: <https://oglobo.globo.com/rio/aldeia-maracana-lixo-urbano-quem-gosta-de-indio-va-parabolivia-diz-rodrigo-amorim-23345028>. Acesso em: 13 nov. 2019.
} 
Figura 8

Regina de Paula,

Teko Haw Brasil.

Aldeia Maracanã, $18 \mathrm{de}$

dezembro de 2019.

Fotografia: José Urutau

Guajajara

Figura 9

José Urutau Guajajara na

Aldeia Maracanã e ao

fundo a passarela que

conecta o Maracanã

com São Cristóvão.

Fotografia: Regina de

Paula
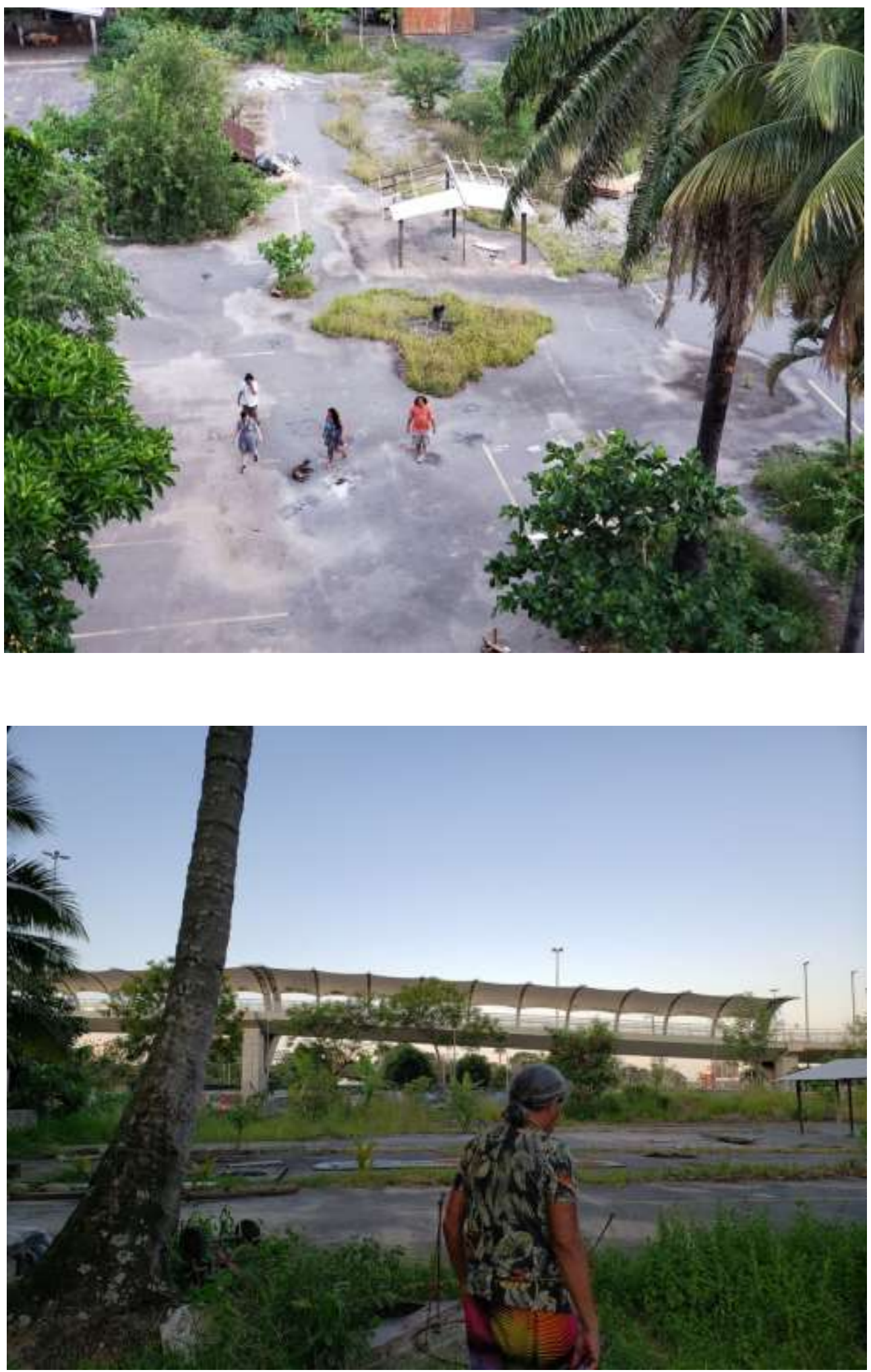
Um dia José Guajajara caminhando nas imediações da aldeia Maracanã ouviu de um passante dirigindo-se a outro: "Eu não disse que isso ia virar uma favelinha? Olhe como está." Ele então subiu a passarela sobre a Radial Oeste que liga São Cristóvão ao Maracanã, na altura da aldeia, e de lá tentou avistar a aldeia para entender aquela opinião e pensou então nas melhorias que a aldeia precisa para estabelecer melhor interface com a cidade. Essa atitude de mediação, de ver com os olhos do outro, a disponibilidade para resistir e integrar, percebidas justamente em cima de uma ponte, um lugar de conexão, pode ser entendida como aquilo que o antropólogo Eduardo Viveiros de Castro, após sua convivência com um povo tupi-guarani amazônico, os Araweté, constatou, conforme nos apresenta Renato Sztutman:

a antropofagia é, como já havia proposto Oswald de Andrade, debruçado na literatura informativa do século XVI, muito mais do que mera refeição cerimonial. Trata-se de uma metafísica que imputa um valor primordial à alteridade e, mais do que isso, que permite comutações de ponto de vista, entre eu e o inimigo, entre 0 humano e o não humano. Isso não seria um atributo exclusivo dos povos tupi-guarani, podendo ser reconhecido como um modo ameríndio de pensar e viver. Eis então o que foi chamado, a partir de um longo mergulho na bibliografia americanista, de perspectivismo ameríndio. ${ }^{20}$

Teko Haw Brasil foi fruto de uma troca, de uma vivência, de um engravidamento pelos ouvidos, como disse Lygia Clark, citada na epígrafe deste texto, a respeito de sua cultura adquirida pela escuta.

Escrevo este texto gravitando entre vozes indígenas e suas ressonâncias, assumindo o risco da perda de estabilidade na transcrição da oralidade para a escrita, rompendo o encadeamento das falas e liberando a palavra. Teko é vida, Haw lugar. Teko Haw Brasil Aldeia Maracanã rexiste!

20 SZTUTMAN, Renato. Apresentação. In: CASTRO, Eduardo Viveiros de. Encontros, 2008. Disponível 
Figura 10

Regina de Paula

Teko Haw Brasil.

Ritual com José Urutau

Guajajara, Potira

Krikati Guajajara e

Ywyrahu Guajajara.

Aldeia Maracanã, 19 de

maio de 2018

Fotografia: Marcus

Moura

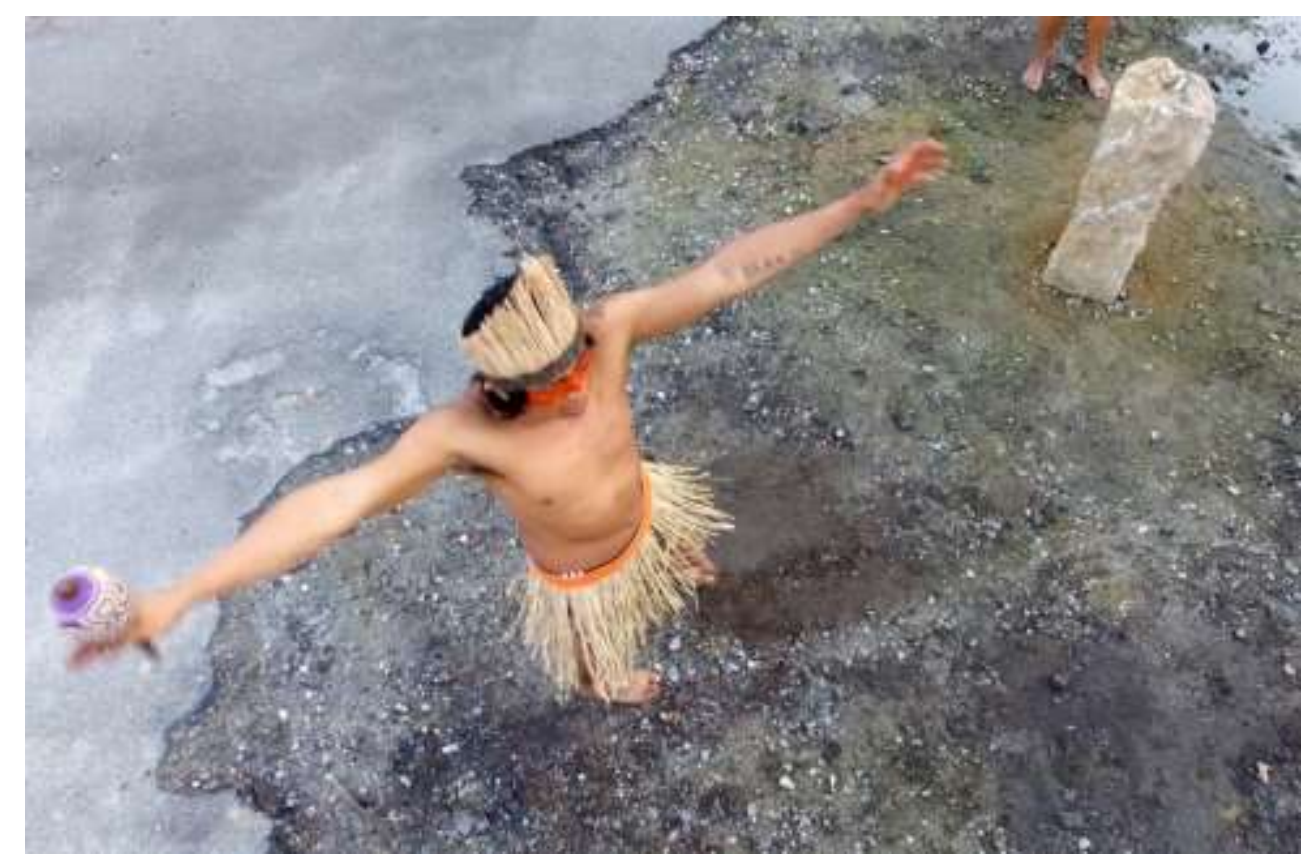

Este é um artigo publicado em acesso aberto sob uma licença Creative Commons

$(\mathrm{cc})$ EY 